\title{
Genetic variability in agronomic traits of a germplasm collection of hulless barley
}

\author{
X.Q. Zeng \\ Barley Improvement and Yak Breeding Key Laboratory, \\ Tibet Academy of Agricultural and Animal Husbandry Sciences, \\ Lhasa, Tibet, China \\ Corresponding author: XQ. Zeng \\ E-mail: xingquanz_2@126.com
}

Genet. Mol. Res. 14 (4): 18356-18369 (2015)

Received August 8, 2015

Accepted October 18, 2015

Published December 23, 2015

DOI http://dx.doi.org/10.4238/2015.December.23.23

ABSTRACT. Germplasm collections represent an important genetic source for crop improvements. In this study, 220 accessions of hulless barley were collected worldwide and their genetic diversity was investigated. Sixteen agronomic traits, including yield and yield components, grain morphology, leaf size, plant height, and lodging resistance, were assessed under field conditions. All studied traits exhibited large variation. Thousand seed weight determined yield, and was strongly affected by spike length and spike number. Four varieties, Gaoyuan Zao 1, Fu 8-4, Zang 0331, and Harry (WDM00618), showed high resistance to lodging. Significant correlations among the traits were observed, indicating trait interactions. Life cycle had the smallest coefficient of variation (CV) among native, foreign, and improved varieties, whereas the $\mathrm{CV}$ of cellulose content was more or less balanced. Among the accessions from domestic and foreign germplasm, the CV for life cycle remained the lowest, whereas those for carbon/nitrogen and spike number per plant were the highest. Interestingly, higher genetic diversity was observed in domestic than in foreign accessions. Together, our findings demonstrate that there is abundant diversity in worldwide hulless barley germplasm collections, which would be useful when introducing 
their desirable traits into cultivars of hulless barley to improve yield and other agronomic traits.

Key words: Hordeum vulgare; Agronomic character; Yield; Lodging resistance

\section{INTRODUCTION}

Hulless barley (Hordeum vulgare L. var. nudum Hook. f.) is a crop of genus Hordeum in family Poaceae. This type of barley has outer hulls that are so loosely attached to the kernel that the kernels usually fall off during harvesting; therefore, hulless barley has also been called "naked barley" (Guo, 1987). Hulless barley is mainly distributed in the Qinghai-Tibet Plateau of China, and in Australia, Mexico, Canada, Japan, Syria, England, Ethiopia, America, Egypt, Germany, Sweden, and France. The Qinghai-Tibet Plateau is the largest area under cultivation for this crop worldwide, and possesses abundant germplasm resources. Hulless barley is used not only as a grain crop (which is sometimes used as organic food), biofuel, and livestock feed, but also as raw material for brewing products such as beer. Recently, it has been found that hulless barley is richer in dietary fiber, hygienic components, and feed nutrients than hulled barley. Therefore, increasing attention has been paid to the breeding and utilization of hulless barley, which has changed from a regional to a global crop.

For crop breeding, modern varieties need to be improved to obtain high yield and quality. However, the narrow genetic basis and genetic erosion of this crop are barriers against the further improvement of yield and quality, which contrasts with the increasing human population of 9.6 billion by 2050 as predicted by the United Nations. Key steps to overcome this problem include the exploration, preservation, and utilization of diversity within germplasm resources (Ma, 2002). A large number of researchers have studied hulless barley based on morphology (Badr et al., 2000; Meng and Zhao, 2006), biochemistry (Izydorczyk et al., 2000; Ehrenberová et al., 2006; Han et al., 2010), cytology (Singh et al., 1970; Søgaard and Wettstein-Knowles, 1987; Zhang, 2000), and molecular biology (Zeng et al., 2002; Feng et al., 2003; Zhang, 2004). However, the use of morphological traits remains the most basic method to analyze initial germplasm resources.

Agronomic traits are involved in plant growth and development as well as in yield formation. Since the 20th century, agronomic trait identification has been a widely used approach because of the ease of measurement and the high relevance to yield (Özcan and Özcan, 2004; Fan and Jiang, 2007). Although various molecular markers have been used to identify the genetic diversity of plant germplasm resources, the large-scale analysis of agronomic traits remains the main driver for crop improvement, and therefore plays a crucial role in agricultural production. Dotlačil et al. (2000) and DeLacy et al. (2000) stated that morphological markers (agronomic traits) are still an effective means to analyze crop genetic diversity. Hence, it is important to fully evaluate and make use of economically important agronomic traits; by doing this, the genetic diversity of germplasm collections can be assessed. Parents that carry contrasting potential traits will be selected to hybridize with currently used cultivars, thereby broadening the genetic basis of crops. The present study was carried out to provide a broad survey of 16 important agronomic traits in 220 hulless barley germplasm accessions collected worldwide. The desirable traits and genotypes thus identified will be useful in the breeding of novel hulless barley cultivars. 


\section{MATERIAL AND METHODS}

\section{Plant materials}

In this study, 220 hulless barley germplasm accessions collected worldwide were used, including 107 native varieties, 38 foreign varieties, and 75 improved varieties (Table S1).

\section{Methods}

Field trials were conducted in the farms of the Tibet Academy of Agricultural and Animal Husbandry Sciences, Tibet, China, according to a completely randomized block design with three replicates, together with a control group Zangqing 2000. Each plot included four rows, with a total area of $2 \times 1 \mathrm{~m}$. The seeds of all plant materials were sowed on April 15, 2012, and agronomic traits were assessed over the following three years. Sixteen traits were investigated: yield and yield components (thousand seed weight, grain length, grain width, spike length, spike grain number, and spike number), canopy architecture (plant height, tiller number, flag leaf length, awn length, and life cycle), and lodging resistance [stem thickness, stem wall thickness, vascular bundle number, carbon/nitrogen $(\mathrm{C} / \mathrm{N})$, and cellulose]. Details of trait measurements are listed in Table 1. All data were analyzed using Microsoft Office Excel 2014 and SPSS v20. Pearson's correlations were used to test the relationships between different traits.

\begin{tabular}{|c|c|}
\hline Trait & Measurement \\
\hline \multicolumn{2}{|l|}{ Yield } \\
\hline Thousand seed weight (TSW, g) & After harvesting, 200 seeds were counted and oven-dried to calculate TSW \\
\hline Grain length $(\mathrm{cm})$ & After harvesting, 50 seeds were selected randomly, and measured using a caliper \\
\hline Grain width $(\mathrm{cm})$ & After harvesting, 50 seeds were selected randomly, and measured using a caliper \\
\hline Spike length $(\mathrm{cm})$ & Ten spikes were measured at maturity, from the bases to tips, excluding awns \\
\hline Spike grain number & Ten spikes were threshed by hand \\
\hline Spike number per plant & Ten plants were counted for tiller number at maturity \\
\hline \multicolumn{2}{|l|}{ Plant architecture } \\
\hline Plant height $(\mathrm{cm})$ & Plant height was measured of ten main shoots at maturity, from the bases to the awns \\
\hline Tiller number & Tiller number was recorded of ten shoots at the trefoil stage \\
\hline Flag leaf length $(\mathrm{cm})$ & Flag leaf length was measured of ten shoots at the milk-ripe stage \\
\hline Awn length $(\mathrm{cm})$ & Awn length was measured of ten shoots at the milk-ripe stage \\
\hline Life cycle & The duration from sowing to maturity was recorded \\
\hline \multicolumn{2}{|l|}{ Lodging resistance } \\
\hline Stem thickness $(\mathrm{cm})$ & The 2nd internodes of stems were sampled and frozen (LEICA CM1850 UV) \\
\hline Stem wall thickness $(\mathrm{cm})$ & For each variety, three sections were used, and three images were taken of each \\
\hline Vascular bundle number & $\begin{array}{l}\text { under } 50 X, 63 X \text {, and } 90 X \text { objectives (OLYMPUS SZX12). Based on these images, } \\
\text { stem thickness, stem wall thickness, and vascular bundle number were measured }\end{array}$ \\
\hline Carbon/nitrogen $(\mathrm{C} / \mathrm{N})$ & $\begin{array}{l}\text { The } 2 \text { nd internodes of stems were used to measure total nitrogen and carbon } \\
\text { content based on the China National Forestry Standards LY/T 1271-1999 and } \\
\text { LY/T 1269-1999 (Buchi K-360), and potassium dichromate oxidation based on } \\
\text { the external heating method of LY/T 1237-1999 }\end{array}$ \\
\hline Cellulose $(\%)$ & $\begin{array}{l}\text { The } 2 \text { nd internodes of stems were used to measure cellulose content at the } \\
\text { dough stage using an ultraviolet spectrophotometer (Mapada UV-3100) }\end{array}$ \\
\hline
\end{tabular}

\section{RESULTS}

\section{Yield and yield components}

Basic statistical analyses of yield and yield components in the hulless barley collection 
are presented in Table 2. The average thousand seed weight was $39.8 \mathrm{~g}$ and ranged from $23.18 \mathrm{~g}$ (Zang 0328) to $51.82 \mathrm{~g}$ (Beiqing 3), with a coefficient of variation (CV) of $8.26 \%$. Figure 1 shows the distribution of thousand seed weight among the varieties. Thousand seed weight ranged from 44 to $47 \mathrm{~g}$ (comprising 59 varieties). Only two varieties showed the maximum thousand seed weight. The CV of grain length and width (8.26\%) were close to that of thousand seed weight, whereas the $\mathrm{CV}$ of spike length and spike number per plant were much higher (39.75\%). The CV of spike grain number $(3.02 \%)$ was the smallest of all the traits analyzed. Thus, large variations were observed in yield and yield components in hulless barley.

\begin{tabular}{|c|c|c|c|c|c|c|}
\hline Statistics & $\begin{array}{l}\text { Thousand seed } \\
\text { weight }(\mathrm{g})\end{array}$ & Grain length $(\mathrm{cm})$ & Grain width $(\mathrm{cm})$ & Spike length $(\mathrm{cm})$ & Spike grain number & Spike number \\
\hline Mean & 39.80 & 0.71 & 0.35 & 6.15 & 46.93 & 4.26 \\
\hline Mean std. error & 0.32 & 0.01 & 0.00 & 0.10 & 1.05 & 0.11 \\
\hline Std. deviation & 4.82 & 0.08 & 0.05 & 1.53 & 15.56 & 1.69 \\
\hline Variance & 23.23 & 0.01 & 0.00 & 2.34 & 241.96 & 2.86 \\
\hline Minimum & 23.38 & 0.50 & 0.23 & 3.00 & 7.20 & 1.00 \\
\hline Maximum & 51.82 & 1.00 & 0.45 & 11.00 & 84.00 & 11.00 \\
\hline Variation coefficient (\%) & 8.26 & 8.60 & 7.53 & 24.89 & 3.02 & 39.75 \\
\hline
\end{tabular}

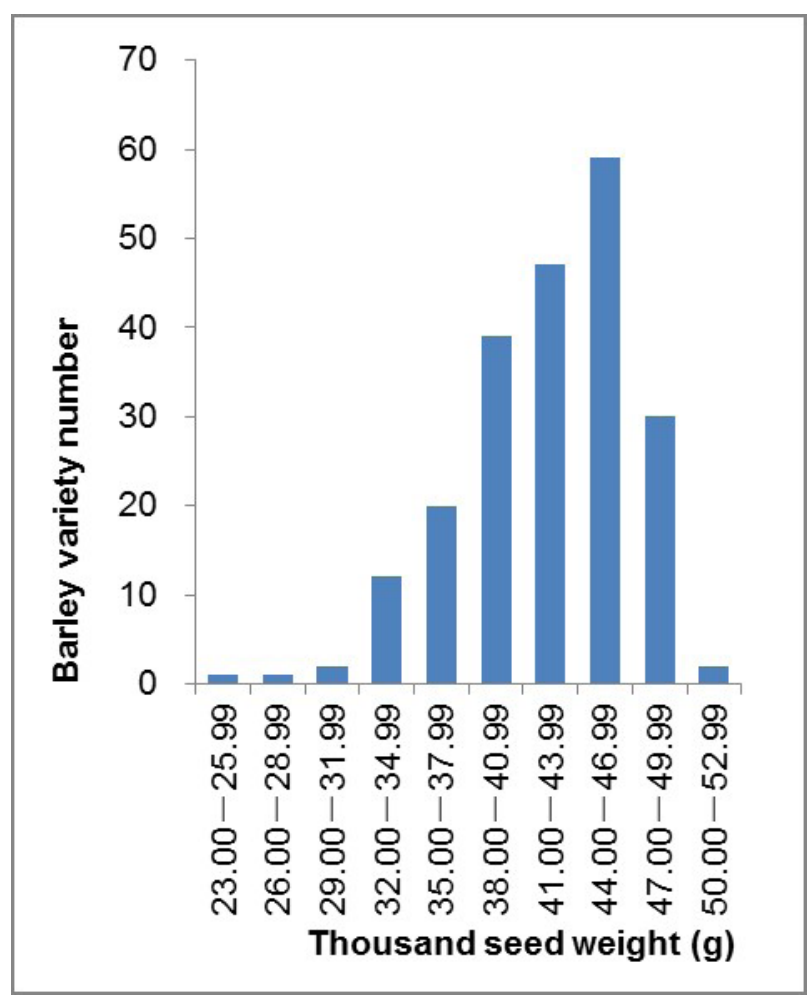

Figure 1. Distribution of thousand seed weight among hulless barley varieties. 


\section{Plant architecture}

Table 3 lists the results of the basic statistical analyses of plant architecture. The average plant height was $79.9 \mathrm{~cm}$, with a CV of $18.18 \%$. The distribution of plant height among the varieties is illustrated in Figure 2. The plant height of major varieties $(28.6 \%)$ ranged from 80 to $90 \mathrm{~cm}$. Over half of all varieties had a plant height lower than $80 \mathrm{~cm}$, including 26 improved varieties, 31 foreign varieties, and 46 native varieties. Figure 3 shows the distribution of total growth duration among the varieties. In total, $44 \%$ of the varieties had growth durations between 110 and $115 \mathrm{~d}$, while an equal distribution of life cycle was between the ranges of 100 to $105 \mathrm{~d}$ and 120 to $125 \mathrm{~d}$. The CV of plant architectural traits followed the trend life cycle < plant height < awn length < tiller number $<$ flag leaf length. The CV of life cycle was the smallest $(5.73 \%)$, and that of flag leaf length was the highest $(74.53 \%)$. Thus, variation in life cycle and plant height was relatively low.

Table 3. Basic statistical analysis of plant architecture-related traits.

\begin{tabular}{lcccrr}
\hline & Plant height $(\mathrm{cm})$ & Tiller number & Flag leaf length $(\mathrm{cm})$ & Awn length $(\mathrm{cm})$ & Life cycle $($ days $)$ \\
\hline Mean & 79.90 & 6.32 & 10.64 & 11.39 & 110.64 \\
Mean std. error & 0.98 & 0.13 & 0.53 & 0.17 & 0.43 \\
Std. deviation & 14.53 & 1.90 & 7.93 & 2.57 & 6.34 \\
Variance & 211.17 & 3.62 & 62.84 & 6.60 & 40.23 \\
Minimum & 6.80 & 3.00 & 3.00 & 1.00 & 100.00 \\
Maximum & 117.00 & 13.00 & 119.00 & 22.56 & 125.00 \\
Variation coefficient $(\%)$ & 18.19 & 30.08 & 74.53 & 5.73 \\
\hline
\end{tabular}

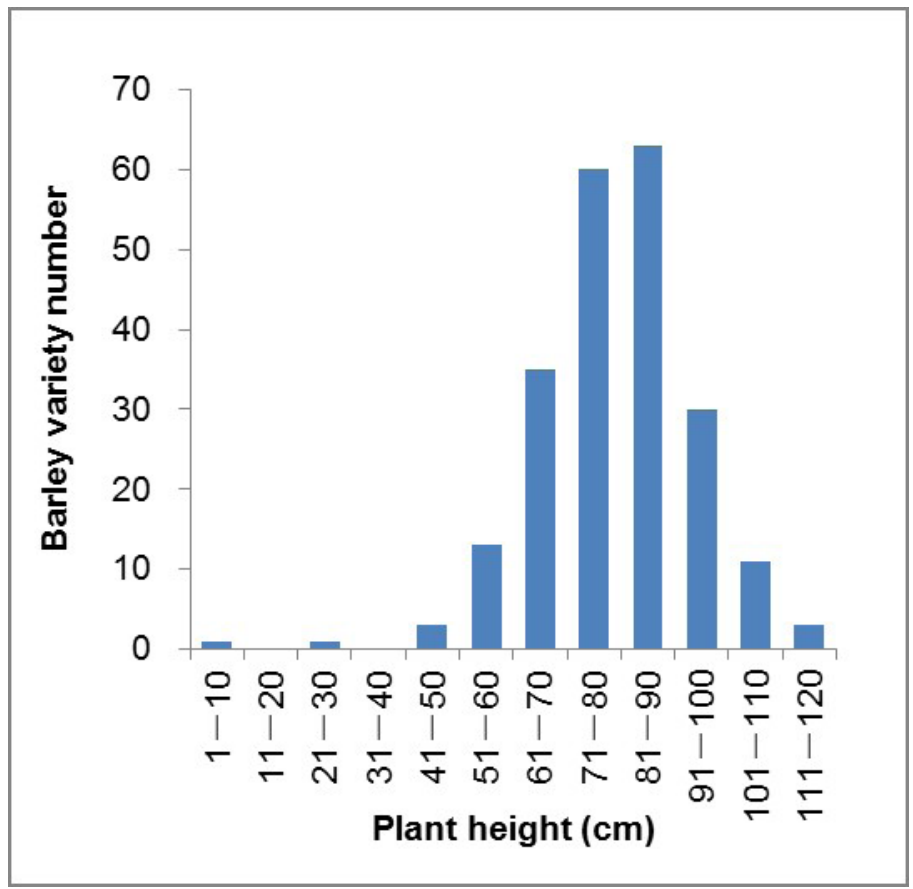

Figure 2. Distribution of plant height among varieties. 


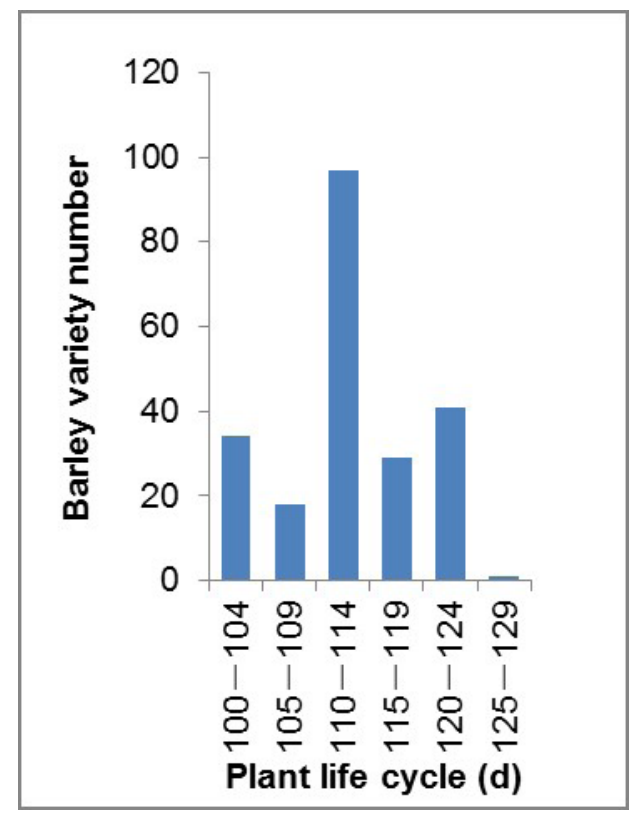

Figure 3. Distribution of life cycle among hulless barley varieties.

\section{Lodging resistance}

Table 4 shows the basic statistical analysis of lodging resistance. The average cellulose content was $22.78 \%$, with a CV of $19.75 \%$. Cellulose content ranged from 8.47 to $32.15 \%$. Figure 4 shows the distribution of cellulose content among the barley varieties. In total, $51 \%$ of the varieties had a cellulose content ranging from 22 to $28 \%$. The average $\mathrm{C} / \mathrm{N}$ was 153.62 , with a high $\mathrm{CV}$ of $33.74 \%$. The $\mathrm{C} / \mathrm{N}$ fluctuated from 49 to 314 . Taking cellulose content, $\mathrm{C} / \mathrm{N}$, vascular bundle number, stem thickness, and stem wall thickness into account, the four varieties with the strongest lodging resistance were Gaoyuan Zao 1, Fu 8-4, Zang 0331, and Harry (WDM00618).

\begin{tabular}{|c|c|c|c|c|c|}
\hline & Stem thickness $(\mathrm{cm})$ & Stem wall thickness $(\mathrm{cm})$ & Vascular bundle number & $\mathrm{C} / \mathrm{N}$ & Cellulose (\%) \\
\hline Mean & 4.13 & 0.65 & 5.98 & 153.62 & 22.78 \\
\hline Mean std. error & 0.77 & 0.01 & 0.11 & 3.49 & 0.30 \\
\hline Std. deviation & 1.14 & 0.16 & 1.63 & 51.83 & 4.50 \\
\hline Variance & 1.29 & 0.03 & 2.67 & 2686.54 & 20.25 \\
\hline Minimum & 2.00 & 0.30 & 4.00 & 49.00 & 8.47 \\
\hline Maximum & 8.90 & 1.20 & 19.00 & 314.00 & 32.15 \\
\hline Variation Coefficient (\%) & 27.53 & 24.39 & 27.30 & 33.74 & 19.75 \\
\hline
\end{tabular}

\section{Correlations of major agronomic traits}

Correlations among major agronomic traits are presented in Table 5. Correlation analysis 
showed that cellulose content was significantly and positively correlated with $\mathrm{C} / \mathrm{N}(\mathrm{r}=0.249)$ and awn length $(r=0.17)$, but negatively correlated with grain width $(r=-0.276)$. Plant height showed significant positive correlations with spike grain number $(r=0.228)$ and stem thickness $(r=0.159)$, and negative correlations with life cycle $(r=-0.236)$, grain length $(r=-0.161)$, and tiller number $(r$ $=-0.157)$. Life cycle showed significant positive correlations with stem wall thickness $(r=0.33)$, grain length $(r=0.329)$, and tiller number $(r=0.193)$, and negative correlations with spike length $(r=-0.243)$ and grain width $(r=-0.157)$. Thousand seed weight showed significantly positive correlations with grain length $(r=0.406)$ and grain width $(r=0.216)$, and a negative correlation with life cycle $(r=-0.344)$. Spike grain number was significantly and positively correlated with stem thickness $(r=0.171)$ and flag leaf length $(r=0.16)$, and was negatively correlated with life cycle $(r=-0.448)$, grain length $(r=-0.294)$, and stem wall thickness $(r=-0.149)$. Significant correlations between traits indicate interactions between them.

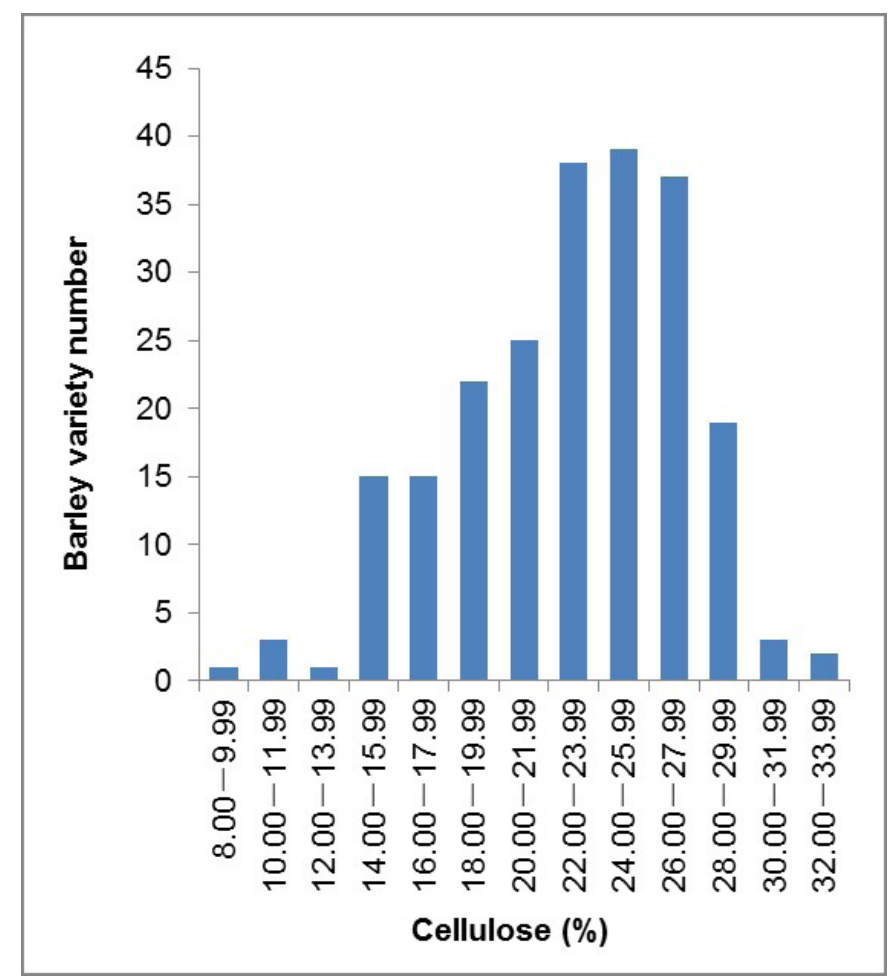

Figure 4. Distribution of cellulose content among hulless barley varieties.

Comparisons of major agronomic traits between domestic (native, improved) and foreign germplasm

Comparisons of major agronomic traits of native, foreign, and improved varieties of hulless barley are presented in Table 6 . The CV of life cycle was the smallest in the native (3.07\%), foreign $(1.65 \%)$ and improved $(4.14 \%)$ varieties. The CV of spike number was highest $(41.83 \%)$ in 107 
native varieties. The CV of spike grain number was highest (47.37\%) in 38 foreign varieties, and the CV of flag leaf length was highest (117.05\%) in 75 improved varieties.

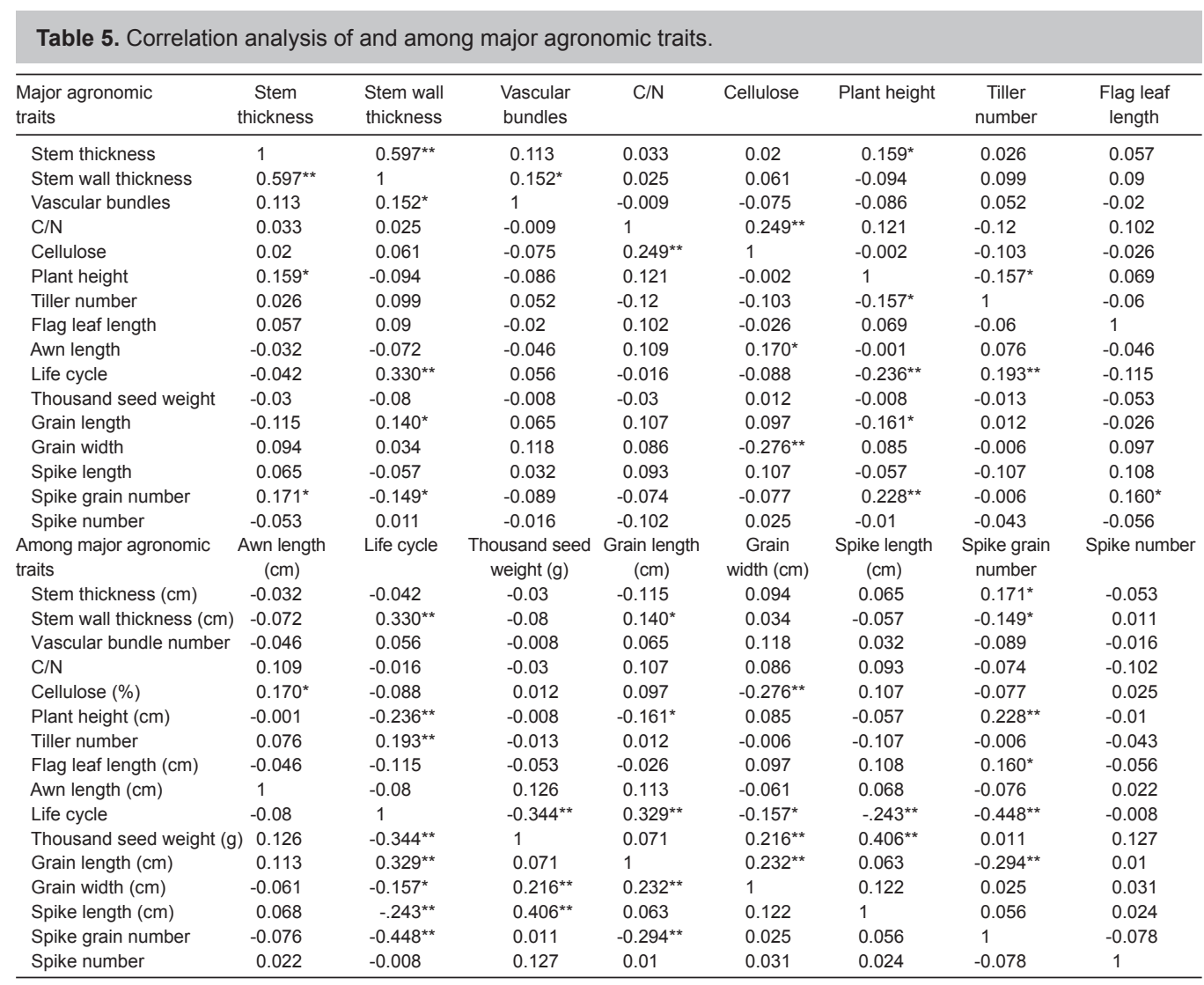

*Significant at $P<0.05$, ** significant at $P<0.01$

The CV of cellulose content among native, foreign, and improved varieties was balanced. The average cellulose content of the native varieties was less than that of the other two groups. The CV of plant height was $8.66 \%$, which was much lower than that of cellulose. In comparison with the $\mathrm{CV}$ of the plant height of the native varieties, the $\mathrm{CV}$ of foreign varieties was fallen to $16.78 \%$. The $\mathrm{CV}$ of thousand seed weight followed the following sequence: improved $(8.76 \%)<$ foreign $(11.72 \%)<$ native $(13.8 \%)$ varieties. The average thousand seed weight of the foreign varieties was higher than that of the native varieties, but lower than that of the improved varieties.

\section{Comparisons of major agronomic traits of varieties of different sources}

Comparisons of major agronomic traits of varieties from different sources are shown in supplementary Table 2. Most of the varieties (82.72\%) were collected from China. Among them, 
there were 133 varieties from Tibet, 27 from Qinghai, 11 from Gansu, 5 from Sichuan, 4 from Yunnan, and from Guizhou. The rest of the varieties (17.28\%) were collected from the other 12 countries. Seven of these varieties were distributed only in Australia and Mexico, six varieties only in Canada and Japan, three varieties in Syria, two varieties only in England, Ethiopia, and America, and one variety in Egypt, Germany, Sweden, and France, respectively.

Table 6. Comparison of major agronomic traits between foreign and domestic germplasm (native and improved).

\begin{tabular}{|c|c|c|c|c|c|c|c|c|c|c|c|c|}
\hline & \multicolumn{4}{|c|}{ Native varieties $(\mathrm{N}=107)$} & \multicolumn{4}{|c|}{ Foreign varieties $(\mathrm{N}=38)$} & \multicolumn{4}{|c|}{ Improved varieties $(\mathrm{N}=75)$} \\
\hline & Mean & Min & Max & $\mathrm{CV} \%$ & Mean & Min & Max & $\mathrm{CV} \%$ & Mean & Min & Max & CV\% \\
\hline Stem thickness $(\mathrm{cm})$ & 4.22 & 2.00 & 8.20 & 26.72 & 3.69 & 2.10 & 5.70 & 23.82 & 4.21 & 2.50 & 8.90 & 29.26 \\
\hline Stem wall thickness $(\mathrm{cm})$ & 0.66 & 0.30 & 1.20 & 23.69 & 0.73 & 0.40 & 1.00 & 19.64 & 0.60 & 0.35 & 1.10 & 26.03 \\
\hline Vascular bundle number & 6.26 & 4.00 & 19.00 & 31.41 & 5.97 & 5.00 & 9.00 & 17.62 & 5.57 & 4.00 & 9.00 & 22.30 \\
\hline $\mathrm{C} / \mathrm{N}$ & 160.65 & 50.00 & 311.00 & 30.93 & 147.34 & 49.00 & 249.00 & 34.97 & 147.81 & 53.00 & 314.00 & 36.60 \\
\hline Cellulose (\%) & 20.86 & 11.45 & 28.00 & 17.47 & 24.65 & 15.46 & 29.98 & 17.01 & 24.66 & 8.47 & 32.15 & 18.56 \\
\hline Plant height $(\mathrm{cm})$ & 82.70 & 6.80 & 117.00 & 20.55 & 67.16 & 48.00 & 100.00 & 16.78 & 82.32 & 65.00 & 105.00 & 8.66 \\
\hline Tiller number & 6.13 & 3.00 & 12.00 & 29.44 & 7.00 & 4.00 & 12.00 & 27.19 & 6.21 & 3.00 & 13.00 & 31.67 \\
\hline Flag leaf length $(\mathrm{cm})$ & 10.93 & 3.00 & 18.70 & 29.56 & 9.31 & 4.00 & 19.00 & 38.84 & 10.92 & 5.00 & 119.00 & 117.05 \\
\hline Awn length $(\mathrm{cm})$ & 10.94 & 1.00 & 14.00 & 25.13 & 11.84 & 6.50 & 16.00 & 15.15 & 11.77 & 8.00 & 18.00 & 21.86 \\
\hline Life cycle & 112.03 & 110.00 & 125.00 & 3.07 & 119.08 & 115.00 & 120.00 & 1.65 & 104.27 & 100.00 & 110.00 & 4.15 \\
\hline Thousand seed weight (g) & 38.33 & 23.38 & 50.82 & 13.08 & 39.49 & 30.58 & 48.96 & 11.72 & 42.09 & 31.18 & 51.82 & 8.76 \\
\hline Grain length $(\mathrm{cm})$ & 0.72 & 0.52 & 0.85 & 9.57 & 0.78 & 0.60 & 1.00 & 10.71 & 0.67 & 0.50 & 0.85 & 10.40 \\
\hline Grain width $(\mathrm{cm})$ & 0.37 & 0.28 & 0.45 & 11.66 & 0.33 & 0.23 & 0.42 & 15.07 & 0.33 & 0.30 & 0.40 & 11.76 \\
\hline Spike length $(\mathrm{cm})$ & 5.98 & 3.00 & 10.00 & 26.61 & 5.92 & 4.00 & 10.00 & 23.02 & 6.69 & 3.00 & 11.00 & 23.81 \\
\hline Spike grain number & 47.17 & 7.20 & 84.00 & 28.83 & 28.42 & 14.00 & 72.00 & 47.37 & 55.95 & 30.00 & 78.00 & 18.28 \\
\hline Spike number & 4.00 & 1.00 & 11.00 & 41.83 & 4.63 & 2.00 & 8.00 & 31.91 & 4.43 & 1.00 & 9.00 & 40.20 \\
\hline
\end{tabular}

The CV of life cycle was the lowest of that of all the traits of the varieties from all the sources. The CV of spike number was the highest $(43.12 \%)$ in Tibetan varieties, while that of tiller number was the highest $(39.57 \%)$ in varieties from Qinghai. The CV of C/N was the highest $(30.84 \%)$ in varieties from Gansu, while CV that of spike number was the highest $(35.29 \%)$ in varieties from Sichuan. The CV of C/N was the highest (46.10\%) in Australian varieties, while that of spike grain number was the highest (41.67\%) in Mexican varieties. The CV of C/N was the highest (62.55\%) in Canadian varieties, while that of spike number was the highest (30.98\%) in Japanese varieties. Thus, the spike number and $\mathrm{C} / \mathrm{N}$ were found to have higher $\mathrm{CV}$ variables than the others.

The average $C / N(n \geq 6)$ from different regions followed the sequence Sichuan $<$ Australia $<$ Canada < Qinghai < Tibet < Mexico < Japan < Gansu. The average cellulose content was highest in Japanese varieties (27.56\%) and lowest in those from Sichuan (16.03\%). The average plant height was highest in Tibetan varieties $(84.06 \mathrm{~cm})$ and lowest in Australian ones $(62.71 \mathrm{~cm})$. The average thousand seed weight was highest in Australian varieties (42.32 g) and lowest in Canadian ones (35.65 g). The average spike grain number was highest in varieties from Sichuan (67.21) and lowest in those from Australia (17.71), with a 4-fold difference between them.

A dendrogram of the major agronomic traits of barley varieties from different regions is presented in Figure 5. Varieties from China were scattered into three clusters. The first one included the varieties from Yunnan and Gansu, which were grouped with the foreign varieties. The second one included the varieties from Sichuan and Guizhou, and the third included the QinghaiTibet Plateau varieties. The first cluster was interesting in that the varieties from Yunnan were first grouped with those from Canada and then with a variety from Gansu. Thus, a richer genetic diversity was observed in domestic than in foreign germplasm. 


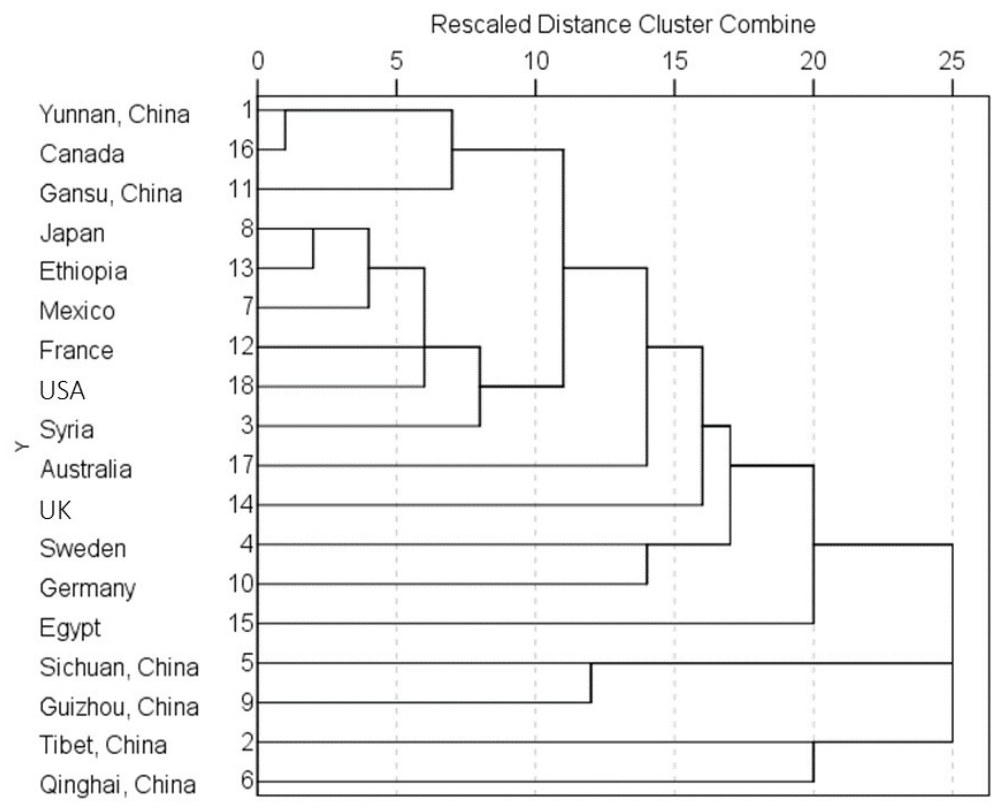

Figure 5. Dendrogram using average linkage (between origins).

As for the foreign germplasm, there was a close relationship among the varieties from Japan, Ethiopia, Mexico, France, America, and Syria. The varieties from Egypt were the most distant from the others. The remaining varieties were from Australia, England, Sweden, and Germany, and had relatively far affinities. Thus, moderate genetic diversity was observed in the foreign germplasm pool.

\section{DISCUSSION}

Germplasm resources are key for the breeding of new varieties of plants, but few studies have evaluated the genetic diversity of the agronomic traits of hulless barley. In this study, we analyzed the correlations and diversity of 16 agronomic traits in 220 varieties, including yield and yield components, plant architecture, and lodging resistance. The discussion below focuses on yield, resistance lodging, correlation, and diversity of hulless barley.

\section{Yield}

Based on the evaluation of 16,251 accessions of barley germplasm resources, Sun et al. (1999) observed high thousand seed weight in varieties from areas of high altitude and latitude, and with a large temperature difference between day and night. This may be due to the thin air in these areas, as well as the high temperature during the day and the low temperature during the night, which would lead to weak respiration. As a result, more assimilates accumulate, resulting in a high yield. Lu (1996) stated that elite barley varieties should have early maturity, dwarfing habit, a large spike, and more grains. Agegnehu et al. (2006) reported that mixed cropping could improve the yield of hulless barley. 
In the present study, the thousand seed weight of domestic, foreign, and improved varieties was $38.33,39.49$, and $48.96 \mathrm{~g}$, respectively. The thousand seed weight of domestic and foreign varieties was similar, but was $20 \%$ lower than that of the improved varieties. This finding is consistent with the result of Sun et al. (1999) that not only with the thousand seed weight but also with the geographic distribution of thousand seed weight.

\section{Lodging resistance}

Compared to other cereal crops, hulless barley has shallow roots and a thin and soft stem, which render it easily lodged when the plants are subjected to strong winds and carry heavy spikes. Therefore, lodging was a main factor causing yield loss of hulless barley. Min et al. (2014) analyzed the lodging mechanisms of hulless barley and found that a reduced plant height is favorable. If plant height is greater than $90 \mathrm{~cm}$, heavy heads, together with weak stem bases, can lead to lodging. Furthermore, elongated basal internode was lack of elasticity and toughness.

Based on the findings for cellulose, $\mathrm{C} / \mathrm{N}$, vascular bundle number, stem thickness, and stem wall thickness, Ithis study identified four varieties with high lodging resistance: Gaoyuan Zao 1, Fu 8-4, Zang 0331, and Harry (WDM00618). Xu (1989) reported that Gaoyuan Zao 1 had dwarf plants and lodging resistance. Ding et al. (1983) reported that Fu 8-4 is also lodging resistant. Nevertheless, Pillen et al. (2004) reported that, in Harry, no significant correlation was found between lodging (at flowering and harvest) and number of ears per square meter, days from sowing to heading, plant height, harvest index, number of kernels per ear, above ground biomass, malt tenderness, grain protein content, thousand grain weight, grain water absorption, or total yield.

In addition, the poor quality of cultivated soil preparation and seeding, improper sowing density, unreasonable field management, and weather damage (such as from strong wind and rain), would also cause lodging of hulless barley. Therefore, lodging-resistant varieties, suitable plant density, effective crop management, and spraying potions can effectively reduce lodging in hulless barley, resulting in stable high yield.

\section{Correlations}

Correlation analyses of 220 varieties of hulless barley germplasm revealed trait interactions. Although the correlation coefficients were low, there were wide correlations among different traits. Hence, a trade-off of key traits should be considered during breeding.

Based on the evaluation of nine agronomic traits of 26 hulless barley cultivars from Qinghai, China, Chen et al. (2012) suggested that the spike number per plant and the thousand grain weight should be considered as a basis for selection. In addition, the negative relationships between spike length and thousand grain weight, and between spike number per plant and grain number per spike should be taken in account. Kraakman et al. (2004) reported that mean yield had a weak negative correlation with yield stability in 146 spring barley cultivars, as observed by linkage disequilibrium mapping. Kraakman et al. (2006) found that plant height was significantly correlated with days to heading in 148 modern spring barley cultivars using AFLP (amplified fragment length polymorphism) and SSR (simple sequence repeat) markers. In our study, a significant negative correlation between thousand seed weight and life cycle indicated that shorter life cycles are associated with higher yields. A significant negative correlation between spike grain number and life cycle indicated that shorter life cycles are associated with more 
grains per spike. A significant positive correlation between life cycle and tiller number indicated that increased tiller number is associated with a longer life cycle. Considering the cool climate, the short frostless season, and the lack of adequate radiation in the area of Qinghai-Tibet Plateau, genotypes with early maturity, short stems, high tiller numbers, and more grains should be selected for breeding, and life cycle, plant height, tiller number, and spike grain number should be used as important breeding indices.

Huang and Pan (2000) investigated correlations between the grain quality and seven agronomic characters in 202 varieties of hulless barley, and found that yield is closely associated with grains per plant and grain weight, and that the key to breeding high-yield plants was to break any negative correlations. Based on the correlation between eight agronomic traits in 107 hulless barley varieties, Li (2010) reported that spike length is significantly positively correlated with spike grain number $(r=0.216)$. Correlation analysis in the present study indicated that thousand seed weight was negatively correlation with life cycle $(r=-0.344)$, spike grain number was negatively correlated with life cycle $(r=-0.448)$, and life cycle was positively correlated with tiller number $(r=$ 0.193); all of these findings were consistent with findings from previous studies.

\section{Diversity}

The Himalayas can be considered a region of domesticated barley diversification (Badr et al., 2000), while Tibet is a potential domestication center of cultivated barley in China (Ren et al., 2013). Due to its complex topography and diverse climate zones, soil types, regional microclimates, and habitat, the Qinghai-Tibet Plateau generates abundant diversity of genetic germplasm. Orabi et al. (2009) documented that their high diversity and close relationship with wild barley make the North African landraces an interesting genetic resource for both conservation and exploitation. Bjørnstad and Abay (2010) reported that varieties of barley from Ethiopia form a very distinct group, with unique diversity in resistance to certain diseases and in morphology, and the average DNA marker or nucleotide diversity was substantially less than that of barley from the Fertile Crescent. Foreign germplasm also showed some diversity. In this study, evaluation of 220 varieties using 16 agronomic traits indicated a richer genetic diversity in domestic than in foreign germplasm. This is consistent with findings from previous studies.

Pan et al. (2007) found that SSR markers, which indicate genetic diversity, are linked with certain important agricultural traits, including resistance to pests and diseases, naked character, starch traits, and malt quality in cultivated naked barley from the Qinghai-Tibet Plateau, suggesting that this is an important gene pool for cereal breeding. Li et al. (2009) analyzed and evaluated eight agronomic traits of germplasm resources and the genetic diversity of 50 barley accessions, and found a high diversity index among the genetic traits of these barley accessions. Yang et al. (2010) revealed high genetic diversity using SSR markers in cultivated hulless barley from the QinghaiTibet Plateau in China. In the present study, our findings relating to plant height, spike length, spike grain number, and thousand seed weight were largely consistent with those reported by $\mathrm{Li}$ et al. (2009). Moreover, our results also indicate that hulless barley exhibits great diversity in many agronomic traits, and this diversity would be valuable for breeding in future decades.

\section{Conflicts of interest}

The authors declare no conflict of interest. 


\section{ACKNOWLEDGMENTS}

Research supported by the following funding sources: the National Program on Key Basic Research Project (\#2012CB723006) the National Science and Technology Support Program (\#2012BAD03B01 and \#2013BAD30B02), and the Tibet Autonomous Region Financial Special Fund (\#2014CZZX001).

\section{Supplementary material}

\section{REFERENCES}

Agegnehu G, Ghizaw A and Sinebo W (2006). Yield performance and land-use efficiency of barley and faba bean mixed cropping in Ethiopian highlands. Eur. J. Agron. 25: 202-207.

Badr A, Müller K, Schäfer-Pregl R, El Rabey H, et al. (2000). On the origin and domestication history of barley (Hordeum vulgare). Mol. Biol. Evol. 17: 499-510.

Bjørnstad A and Abay F (2010). Multivariate patterns of diversity in Ethiopian barleys. Crop Sci. 50: 1579-1586.

Chen LH, Zhang ZB, Hou ZQ, Deng XQ, et al. (2012). Analysis of agronomic characters of major hulless barley cultivars in Qinghai Province. Acta Agric. Univ. Jiangxiensis 34: 439-444.

DeLacy IH, Skovmand B and Huerta J (2000). Characterization of Mexican wheat land races using agronomically useful attributes. Genet. Resour. Crop Evol. 47: 591-602.

Ding WB, Wang JQ, Feng RC and Feng YQ (1983) "Ba 19 Fu 8-4”. In: Qinghai Crop Variety (Liu QY, ed.). Qinghai People's Publishing House, Xining.

Dotlačil L, Hermuth J, Stehno Z and Manev M (2000). Diversity in European winter wheat land races and obsolete cultivars. Czech J. Genet. Plant Breed. 36: 29-36.

Ehrenberová J, Belcrediová N, Prýma J, Vaculová, et al. (2006). Effect of cultivar, year grown, and cropping system on the content of tocopherols and tocotrienols in grains of hulled and hulless barley. Plant Foods Hum. Nutr. 61: 145-150.

Fan SX and Jiang YR (2007). Study status and progress in Fenton method. Modern Chem. Ind. 27: 104-107.

Feng ZY, Zhang YZ, Zhang LL and Ling HQ (2003). Genetic diversity and geographical differentiation of Hordeum vulgare ssp. spontaneum in Tibet using microsatellite markers. High Tech. Lett. 13: 57-61.

Guo BZ (1987). Economic Plants of Qinghai in China. Qinghai People's Publishing House, Xining.

Han Z, Wu F, Deng G, Qian G, et al. (2010). Structural and expressional analysis of the B-hordein genes in Tibetan hull-less barley. Genetica 138: 227-239.

Huang ZL and Pan YP (2000). Path analysis of quality and agronomic characters in barley germplasm. J. Yangzhou Univ. (Nat. Sci. Edn.) 3: 36-40.

Izydorczyk MS, Storsley J, Labossiere D, MacGregor AW, et al. (2000). Variation in Total and Soluble $\beta$-Glucan Content in Hulless Barley: Effects of Thermal, Physical, and Enzymic Treatments. J. Agric. Food Chem. 48: 982-989.

Kraakman ATW, Niks RE, Van den Berg PMMM, Stam P, et al. (2004). Linkage disequilibrium mapping of yield and yield stability in modern spring barley cultivars. Genetics 168: 435-446.

Kraakman ATW, Martínez F, Mussiraliev B, van Eeuwijk FA, et al. (2006). Linkage disequilibrium mapping of morphological, resistance, and other agronomically relevant traits in modern spring barley cultivars. Mol. Breed. 17: 41-58.

Li SM (2010). The Study on Genetic Diversity of Germplasm Resource in Barley. Shihezi City, Xinjiang Province, Shihezi University.

Li SM, Liang W, Wei LJ, Qi JC, et al. (2009). Agronomic trait of germplasm resources and genetic diversity of hordein in Xinjiang Barley. Xinjiang Agric. Sci. 46: 269-274.

Lu LN (1996). China Barley. Chinese Agriculture Press, Beijing, 119-122.

Ma DQ (2002). Genetic Resources of Tibetan Barley in China. China Agriculture Press, Beijing.

Meng FL, Zhao YB, Qiang XL, and Hu YG (2006). Comparison on agronomic traits of Barley from different regions and improvement of Tibet naked barley. J. Triticeae Crops 26: 175-178.

Min K, Wang WJ and Choying D (2014). Highland barley lodging resistance technology research. Barley Cereal Sci. 1: 13-14.

Orabi J, Jahoor A and Backes $G$ (2009). Genetic diversity and population structure of wild and cultivated barley from West Asia and North Africa. Plant Breed. 128: 606-614.

Özcan AS and ÖOzcan A (2004). Adsorption of acid dyes from aqueous solutions onto acid-activated bentonite. J. Colloid Interface Sci. 276: 39-46. 
Pan ZF, Zhou YX, Deng GB, Zhai XG, et al. (2007). Genetic diversity of SSR markers in cultivated hulless barley from Qinghai Tibet Plateau in China. Acta Sci. Nat. Univ. Sunyatseni 46: 82-86.

Pillen K., Zacharias A and Léon J (2004). Comparative AB-QTL analysis in barley using a single exotic donor of Hordeum vulgare ssp. spontaneum. Theor. Appl. Genet. 108: 1591-1601.

Ren X, Nevo E, Sun D and Sun G (2013). Tibet as a potential domestication center of cultivated barley of China. PLoS One 8: e62700.

Singh MP, Kalia CS and Jain HK (1970). Chromosomal aberrations induced in barley by LSD. Science 169: $491-492$.

Søgaard B and von Wettstein-Knowles P (1987). Barley: genes and chromosomes. Carlsberg Res. Commun. 52: $123-196$.

Sun LJ, Lu W, Zhang J and Zhang WX (1999). Evaluation and utilization of barley germplasm resources of China. Sci. Agric. Sin. 2: 24-31.

Xu CQ (1989). "294 Gaoyuan Zao 1". In: China Barley Variety, (Zhejiang Academy of Agricultural Sciences and Qinghai Academy of Agricultural Sciences, eds.). Agriculture Press, Beijing, 272.

Yang J, Chi DZ, Wu KL, He GF. (2010). Genetic diversity of SSR markers in cultivated Hordeum vulgare L. in Qinghai Province. J. Anhui Agric. Sci. 38: 4307-4309.

Zeng Y, Lan LQ, Luo H, Bai J, et al. (2002). RAPD markers in diversity detection and variety identification of Tibetan Hulless Barley. Plant Mol. Biol. Report. 20: 369-377.

Zhang LT (2000). Identification of Hordeum vulgare - H bulbosum recombinants using cytological and molecular methods. Doctoral thesis, Biological Sciences, University of Auckland.

Zhang Q (2004). SSR marker tagging of two new dwarfing genes in barley (Hordeum vulgare L.). J. Plant Genet. Resour. 5: 105-109. 